\title{
THE SYSTEMATIC POSITION OF GLYPHOLOMA JEANNEL, WITH A NEW SYNONYMY (COLEOPTERA: SILPHIDAE, STAPHYLINIDAE)*
}

\author{
By Alfred F. Newton, Jr. \\ Museum of Comparative Zoology, Harvard \\ University, Cambridge, Mass. 02138
}

\section{INTRODUCTION}

In 1962 R. Jeannel described Glypholoma pustuliferum, a new genus and species of an interesting small beetle from southern Chile for which he created a new tribe in the family Silphidae. A similarlooking beetle from southern Argentina was more recently described by $\mathrm{O}$. Scheerpeltz as Lathrimaeodes pustulipenne, a new genus and species of the staphylinid sub-family Omaliinae. The two species have apparently not been compared to one another or otherwise mentioned in the literature. Since neither author gave detailed reasons for the placement of his genus, and neither mentioned several characters that are now considered essential to such placement, the systematic position of these genera may be considered unsettled.

A small series of specimens which agrees with the descriptions of both of the above species is in the collection of the Museum of Comparative Zoology. Based on an examination of these specimens and on the information given in the original descriptions, I would here like to present evidence for the synonymy of the two names, to expand upon the published descriptions, and to reconsider the relationships of the genus. This paper is also intended as an initial contribution to a revision of the classification and phylogeny of Staphylinoidea.

\section{Synonymy and Distribution}

A careful comparison of the description and figures of Glypholoma pustuliferum by Jeannel (1962) with the more detailed description and photograph of Lathrimaeodes pustulipenne by Scheerpeltz (1972) leaves no doubt that the two species are extremely closely allied. The agreement is so complete that there is nothing to suggest that more than one species is involved. G. pustuliferum was recorded from Chile Chico (type locality) and Rio Murta at about $46^{\circ} 30^{\prime}$ S latitude

\footnotetext{
*Published with the aid of a grant from the Museum of Comparative Zoology.

Manuscript received by the editor May 5, 1975
} 
in the southern Andes of Aisen Province, Chile; and from the vicinity of Punta Arenas and Boqueron in the Magellan Strait area, Magellenes Province, Chile, at about $35^{\circ} 30^{\prime}$ S latitude. Habitat data were not given, but these localities are within the Nothofagus forest zone. L. pustulipenne was recorded from 27 sites in the vicinity of El Bolsón, Rio Negro Province, and El Puelo and El Turbio, Chubut Province, Argentina, all at about $42^{\circ} \mathrm{S}$ latitude on the east slope of the southern Andes. The large series were found between 220 and II7O meters, nearly all by sifting ground litter in forests of Nothofagus, Libocedrus and other trees. The pustulipenne localities are thus little more than half as far removed from the pustuliferum type locality as the Magallanes records of the latter species, and in the same mountain range. Because of the relative completeness of the original descriptions and the distinctiveness of the species, I have not felt it necessary to examine type material, but believe that the combination of morphological agreement and apparent continuity of habitat of the two nominal species is sufficiently strong evidence of conspecificity to formally synonymize the two names. Lathrimaeodes pustulipenne Scheerpeltz hence becomes a junior synonym of Glypholoma pustuliferum Jeannel (NEW SYNONYMY).

In addition to the material recorded in the original descriptions, which should be consulted for complete collection data, six specimens labeled "Punta Arenas, Chile, Feb. 'o6, R. Thaxter" are in the Museum of Comparative Zoology. The following descriptive notes and illustrations have been taken from these specimens.

\section{Partial Redescription}

Each of the original descriptions provides a habitus illustration and sufficiently treats the external characteristics of the species for recognition purposes. Here I would like to describe or illustrate several features of systematic importance that were covered incompletely or not at all in those descriptions.

Head capsule shaped as in Fig. I, with a transverse V-shaped sulcus in the frontal region. This sulcus is the external indication of an internal ridge connecting the anterior attachments of the tentorium. From the middle of this sulcus a faint sulcus runs a short distance posteriorly. Mandible (fig. 2) with a well developed molar lobe at base. Maxilla and labium as in fig. 3.

Prothorax with coxal cavities as in fig. 4. Hind coxa strongly excavate (fig. 5), the postero-ventral edge produced into a thin plate capable of covering more than half of the femur in repose. Metendo- 

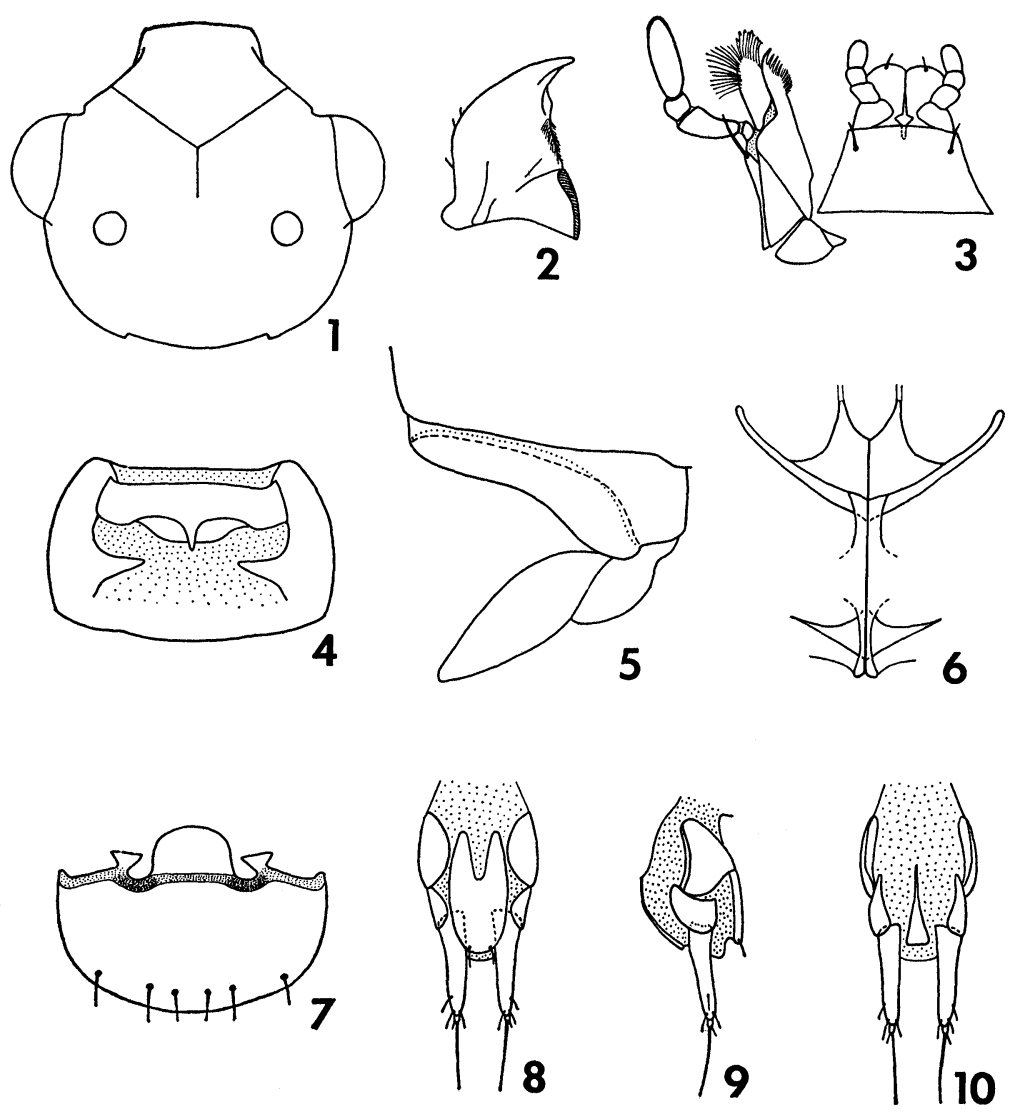

Figs. 1-10. Glypholoma pustuliferum Jeannel.

1. Head capsule, dorsal view. 2. Right mandible, ventral view. 3. Labium and right maxilla, ventral view. 4. Prothorax, ventral view, legs removed. 5. Right metacoxa and femur, ventral view (dotted line $=$ extent of coxal cavity, dashed line $=$ postero-dorsal edge of coxa). 6. Metendosternite, dorsal view. 7. Eighth abdominal sternite, ventral view. 8.-10. External female genitalia (membranous areas stippled); 8., dorsal; 9., left lateral; 10., ventral view. Not drawn to scale. 
sternite as in Fig. 6, the dorsal flange of the stalk flaired out into membrane at the middle. Elytra covering all of the first four abdominal tergites, the fifth tergite partially exposed. Folding pattern of hind wing similar to that illustrated for Anthobium (=Eusphalerum) sorbi by Forbes (1926: fig. 33), the first transverse fold being a hinge in which the costal margin is turned about $90^{\circ}$.

Tergites of abdominal segments 2 and 3 sclerotized to some degree, those of fourth and following segments more strongly so. Tergites 4 and 5 each with a pair of patches of short, pale, mesally-directed setae, the patches together covering most of the surface of the tergite. Sternite 8 with complex anterior modification as in fig. 7 . Intersegmental membranes of abdomen with rectangular plates arranged in a brick-wall-like pattern.

Male genital segment and aedeagus as illustrated by Jeannel (1962: figs. IO, II), except that both figures are ventral rather than dorsal views as stated. Pleurites of genital segment narrowly connected anterior to tergite. Parameres of aedeagus in repose in abdomen facing dorsally. Female external genitalia as in figs. 8-io.

\section{Discussion}

Jeannel considered Glypholoma to be closely allied to the silphid tribe Pterolomini. He differentiated it from that tribe by the structure of the maxillary palpus, with a very short third segment, and by what he considered a very unusual aedeagus. Scheerpeltz placed the genus in the Omaliinae and considered it closely related to Lathrimaeum (=Anthobium of current usage). He separated it from Anthobium by the absence of a nuchal sulcus and by the longer and differently sculptured elytra.

In considering the placement of the two long-controversial genera Brathinus and Camioleum, Hammond (197I) has reviewed and augmented the characters of the Omaliinae that are useful in distinguishing them from other Staphylinoidea. Glypholoma has all I I of the mentioned features. The three characters that will immediately exclude Glypholoma from association with Pterolomini and allied tribes of Silphidae are: I) the hinging of the costal margin of the hind wing during folding, whereas the costal margin is folded back on itself in primitive Silphidae as illustrated for Necrophilus hydrophiloides by Forbes (1922: fig. 27);2) the anterior modification of the eighth sternite, whereas Silphidae have at most a simple median projection; and 3) the structure of the aedeagus with a large lightly sclerotized basal bulb, short median lobe and small median foramen, 
whereas in Pterolomini and allies the aedeagus is a large heavily sclerotized tubular structure without basal bulb and with a large median foramen. The characteristically modified eighth sternite is restricted, according to Hammond, to the staphylinid subfamilies Proteininae and Omaliinae and the genus Empelus which probably belongs near those subfamilies. The two additional characters of Glypholoma that specifically place it in the Omaliinae are the presence of a pair of ocelli on the vertex of the head, and the presence of paired setal patches on abdominal tergites 4 and 5 .

Within the Omaliinae the general habitus, palpal and tarsal structure and nearly all other features indicate a close relationship of Glypholoma to Anthobium and related Holarctic genera such as Mathrilaeum, Camioleum, Deliphrum and Olophrum, as originally proposed by Scheerpeltz. Hammond (op. cit.) has pointed out that this generic group is badly in need of worldwide revision and that the generic concepts will probably change when this is done. At the present time I can only point out what appear to be three exceptional features of Glypholoma that may be unique in the Omaliinae, based on the literature and on examination of the omaliine genera in the Museum of Comparative Zoology. These are: I) the pustules on the elytra referred to by both original authors; 2 ) the excavate hind coxae, also found in Empelus; and 3) the Y-shaped sulcus on the head capsule.

The distribution of the last-mentioned character merits special attention. To my knowledge $\mathrm{Y}$-shaped sulci have been previously reported only in the staphylinid tribe Tachyporini among Staphylinoidea (Blackwelder 1936), but are much more widespread. In addition to all genera of that tribe and Glypholoma, I have confirmed them in: Staphylinidae - Trigonurus spp. (Piestinae) and Habrocerus magnus (of uncertain position, not a true Habrocerus); Silphidae - Nicrophorus spp. (Silphinae) and Pelatines latus and Lyrosoma opaca (Agyrtinae); Leiodidae - Catopocerus spp. (Catopocerinae), several genera of Agyrtodini (Catopinae), and an unidentified Tasmanian genus of Neopelatopini (Leiodinae). Such sulci are well-known features of many members of the related superfamily Hydrophiloidea. They have been considered absent from Histeroidea, the third group of Staphyliniformia (Crowson 1974), but are found in Sphaerites politus (Sphaeritidae) and at least some species of the histerid genera Bacanius and Idolia. Consideration of the origin and functional significance of this structure is beyond the scope of the present work. However, this widespread distribution among what many would consider primitive members of the three related super- 
families, and absence from clearly derivative forms, suggests that the presence of the $\mathrm{Y}$ sulcus is an ancestral feature of Staphyliniformia. In Glypholoma it is therefore probably best interpreted as a primitive condition which has been lost in other Omaliinae.

\section{ACKNOWLEDGMENTS}

I wish to thank P. M. Hammond for calling my attention to the description of Lathrimaeodes, and T. F. Hlavac and J. F. Lawrence for reading and commenting on the manuscript.

\section{RefEREnces}

BLACKWELder, R. E.

1936. Morphology of the coleopterous family Staphylinidae. Smiths. Crowson, R. A. Misc. Coll. 94 (13), 102 pp.

1974. Observation on Histeroidea, with descriptions of an apterous larviform male and of the internal anatomy of a male Sphaerites. FORBES, W. T. M. J. Ent. (B) 42 (2) : 133-140.

1922. The wing-venation of the Coleoptera. Ann. Ent. Soc. Amer. 15: 328-345.

1926. The wing folding patterns of the Coleoptera. J. N. Y. Ent. Soc. 34: 42-68, 91-115.

\section{HAMmond, P. M.}

1971. The systematic position of Brathinus LeConte and Camioleum JEANNEL, $\mathbf{R}$. Lewis (Coleoptera: Staphylinidae). J. Ent. (B) 40 (1): 63-70.

1962. Les Silphidae, Liodidae, Camiaridae et Catopidae de la Paléantarctide Occidentale. Biol. de l'Amér. Aust. 1: 481-525. SCHEERPELTZ, O.

1972. Wissenschaftliche Ergebnisse der Studienreise von Gy. Topal nach Südwest-Argentinien (Coleoptera: Staphylinidae). Folia Ent. Hung. (Series Nova) 25, Suppl., 268 pp., 5 pl. 

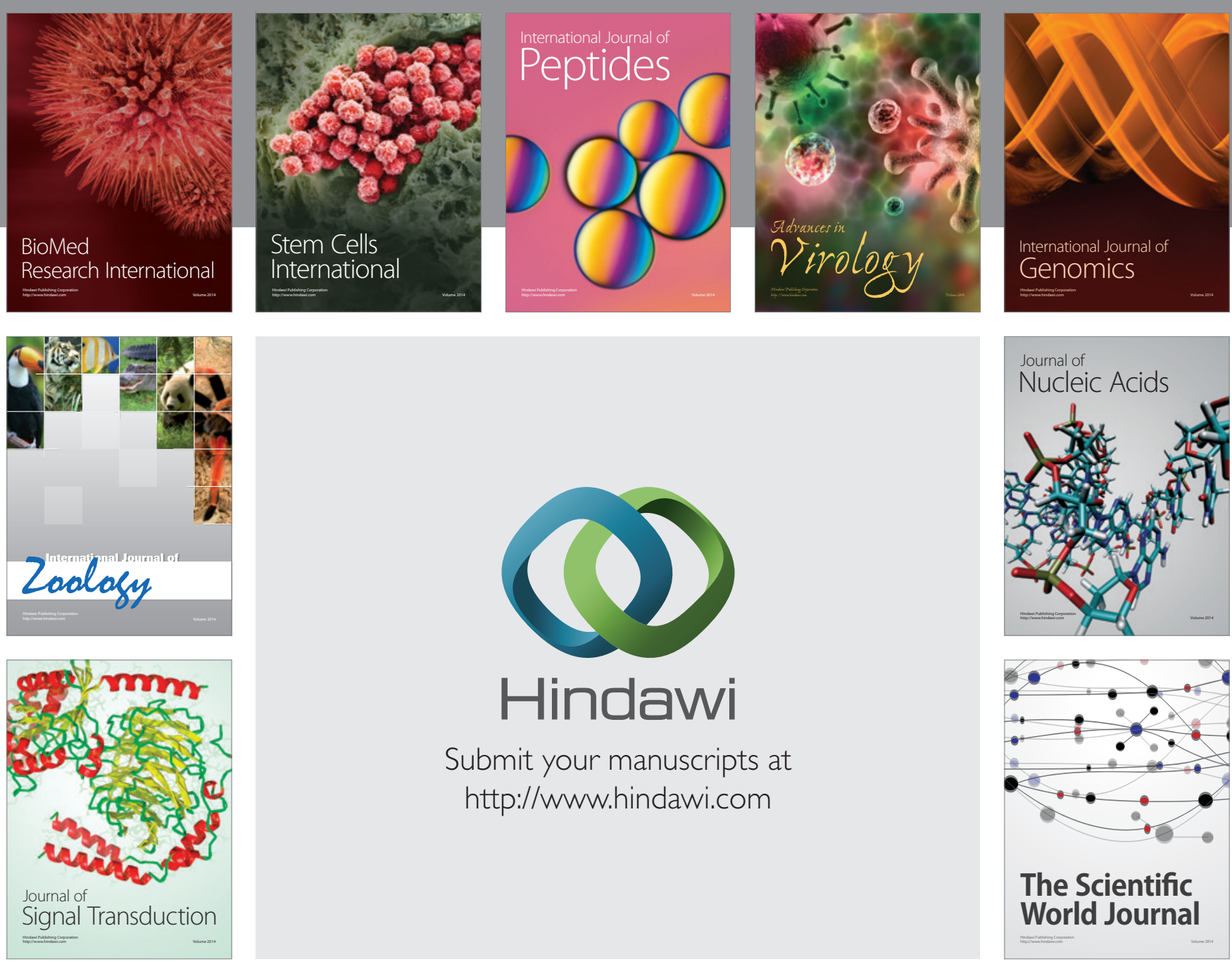

Submit your manuscripts at

http://www.hindawi.com
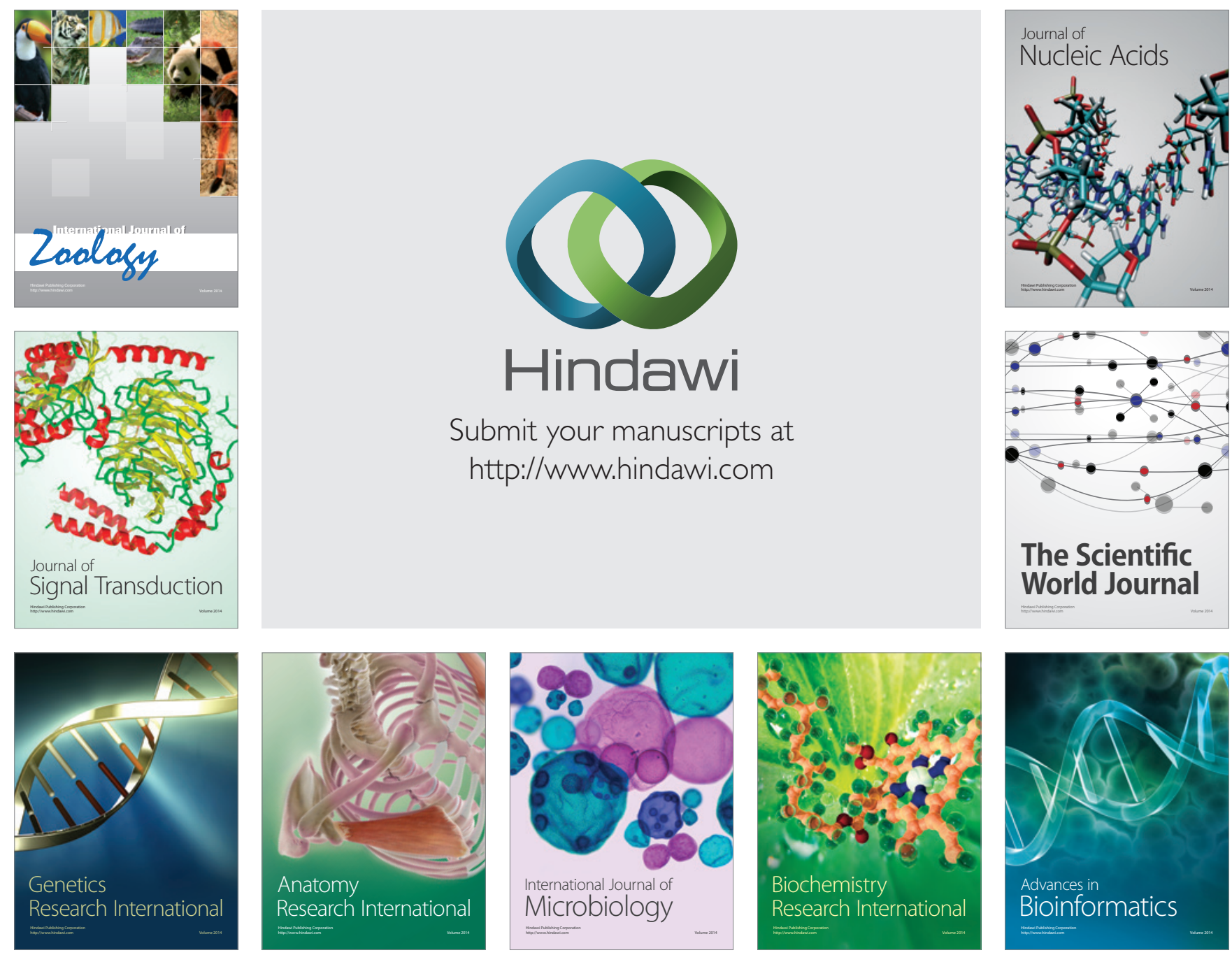

The Scientific World Journal
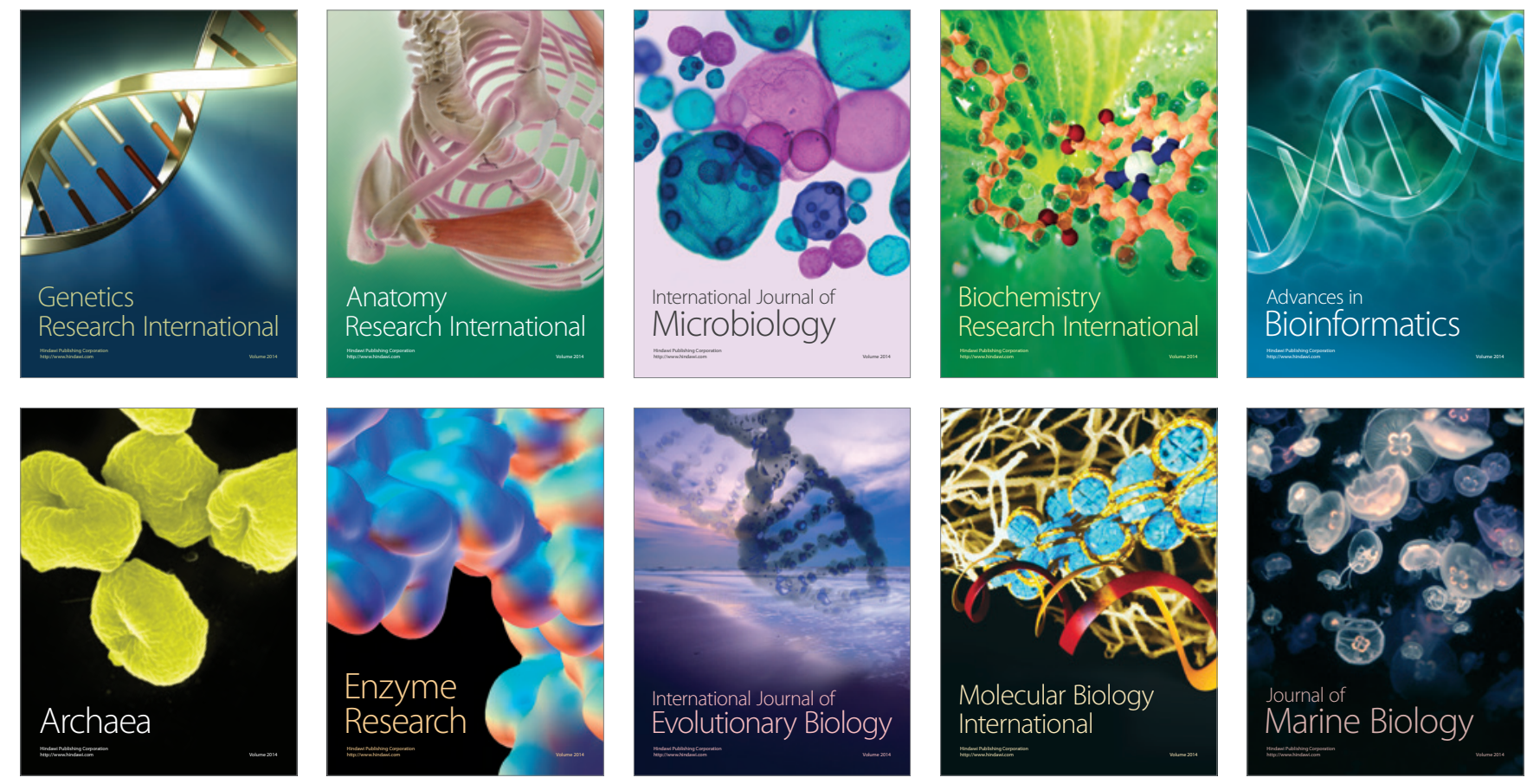